\section{耍 Heighten Science P U B L I C I T I O N S Corporation ISSN 2575-0186}

\title{
Associations of Burnout, Secondary Traumatic Stress and Individual Differences among Correctional Psychologists
}

\author{
Irina G. Malkina-Pykh* \\ Research Center for Interdisciplinary, Environmental Cooperation, Russian Academy of \\ Science, Russia
}

\begin{abstract}
*Address for Correspondence: Irina G. MalkinaPykh, Research Center for Interdisciplinary, Environmental Cooperation, Russian Academy of Sciences (INENCO RAS), Saint-Petersburg, 191187, nab. Kutuzova, 14 Russia, Tel: +7(812)2721601, +7(961)8099247; Email: malkina@mail.admiral.ru

Submitted: 19 December 2016

Approved: 23 January 2017

Published: 25 January 2017

Copyright: @ 2017 Malkina-Pykh. This is an open access article distributed under the Creative Commons Attribution License, which permits unrestricted use, distribution, and reproduction in any medium, provided the original work is properly cited.
\end{abstract}

Keywords: Correctional psychologists; Burnout; Secondary traumatic stress; World-view model; Locus of control

\section{ABSTRACT}

Objective: The aim of the present study was to examine associations between secondary traumatic stress (ST), job burnout (BO) and several psychological variables such as world assumptions and locus of control in correctional psychologists.

Methods: This study utilized information provided by 87 currently prac-ticing correctional mental health providers (psychologists) in the correctional settings across Russia in St.-Petersburg, Belgorod, Vladimir, Kaluga, Ryazan, etc. The sample included 51 men, 36 women. The mean age of participants was $34.9 \pm 6.9$ (ranging from 25 to 48 years). Participants reported working a mean of $6.23 \pm 3.5$ years (ranging from 3 months to 15 years) in a correc-tional setting. Subjects were assessed with Maslach Burnout Inventory-Human Services Survey (MBI-HSS), Secondary Traumatic Stress Scale (STSS), World Assumption Scale (WAS) and Locus of Control (LC) Scale. Three sets of statistical analysis were provided: ANOVAs between- group comparisons with $\mathrm{STS}$ and $\mathrm{BO}$ as factors and Spearman correlation analyses.

Results: The results of our study reveal that burnout and secondary traumatic stress in correctional psychologists are significantly positively related and thus may be exacerbated by each other. BO is significantly negatively associated with WAS benevolence scale and the WAS self worth scale and STS is significantly negatively associated with WAS benevolence scale and the WAS meaningfulness scale. However, LC and its components are negatively associated with $\mathrm{BO}$, but not with STS

Conclusion: The main future direction of our research is to construct nonlinear model of burnout with STS, WA and LC components as predictors, identify its parameters and make its validation.

\section{INTRODUCTION}

Correctional facilities have been described as unique, dangerous and highly stressful work environment [1]. Within the correctional environment, the work experiences of psychologists might be different than psychologists employed in medical settings, public psychiatric hospitals, and counseling centers.

Correctional mental health professionals (psychologists) are defined as psychologists that works in a correctional setting (i.e., prison, jail, correctional facility, etc.) [2]. They are one of the primary providers of mental health services in correctional facilities [3]. In addition to providing direct services to inmates in the form of individual or group therapy, crisis and suicide intervention services, psychological and risk of violence assessments and psychoeducational groups, correctional mental health professionals often fill many other roles within a correctional facility. Such roles include providing services to correctional staff, reducing tensions, enhancing 
safety, and working in management/administrative capacities to craft and implement appropriate and beneficial policies [4-6]. They are also in a position to aid individuals in the shift from inmate to citizen in postincarceration reintegration plans [7], thereby reducing the likelihood that the inmate will return to a criminal lifestyle upon release.

Additionally, correctional work is frequently described as unique social microcosm that is characterized by (a) a para-military staff hierarchy, (b) an "us versus them" separation between staff and offenders, (c) continual separation from mainstream society, (d) a perceived hierarchy among the offenders that is often linked to their respective crimes, (e) an obvious presence of gangs, and (f) social pressure among the offenders themselves to conform to antisocial values $[8,9]$. Consequently, correctional psychologists need to be clearly and explicitly aware of about the value system within which they are performing their duties. Moreover, such an ethical standard goes beyond knowing one's own values and having sensitivity to the values of one's client, but also involves knowing the values of the correctional social context itself (i.e., safety of the public, security of the institution, good order of the institution, etc.) [10]. Unfortunately, researches on the effects of doing this work (e.g., burnout and/or secondary traumatic stress) are extremely rare.

In 1974, Freudenberger defined employee burnout (BO) as a situation when an employee was exhausted psychologically as well as physically due to work place situations [11]. Maslach and Jackson defined burnout as "a syndrome of emotional exhaustion and cynicism that occurs frequently among individuals who work with people" (p.99) [12]. Burnout has been conceptualized as a construct consisted of three dimensions: emotional exhaustion (the emotional manifestation of chronic fatigue or stress); depersonalization (callousness or lack of concern regarding clients or patients); and a decrease in the perception of personal accomplishment (the perception of enthusiasm and effectiveness that comes from working with people) $[12,13]$.

Close but not similar to burnout, as defined by [12], are concepts of "vicarious traumatization (VT)" [14,15], "compasion fatigue (CF)" [16] and "secondary traumatic stress (STS)" $[17,18]$. All three concepts identify and define the traumatization of helpers resulted from their efforts of helping as well as describe the deleterious effects that helpers suffer when working with traumatized clients. Although there is overlap between the concepts underlying these terms, there are also differences.

Secondary traumatic stress "is the stress resulting from wanting to help a traumatized or suffering person" [16]. Secondary traumatic stress also has been defined as a result of "work-related, secondary exposure to traumatic events" [19] and a "state of tension and preoccupation with the traumatized patients by reexperiencing the traumatic events, avoidance/numbing of reminders, and persistent arousal (e.g., anxiety) associated with the patient" [20]. Chrestman noted that secondary traumatization of clinicians has been hypothesized to include symptoms parallel to those observed in persons directly exposed to trauma [21]. Thus, secondary traumatic stress is a syndrome of symptoms nearly identical to those of post-traumatic stress disorder (PTSD), including symptoms of intrusion, avoidance, and arousal [22].

Given that corrections professionals are routinely exposed to multiple types of stressors concurrently in correctional settings, such as organizational, operational and traumatic, an umbrella term "Corrections Fatigue" has been proposed to more fully capture the range of stressors and types of exposure that can and do operate in corrections settings [23]. Stamm states that secondary traumatic stress is a better term to use as it is more broad and vicarious traumatization and compassion fatigue are actually specific types of secondary traumatic stress [24]. However, in his later studies Stamm defined CF as incorporated into two parts: STS and burnout (BO) [25].

Figley has suggested [20], that secondary trauma is not the same as burnout 
syndrome and that each should be treated as having a unique effect on a professional's well-being (see also, [26-28]). Burnout is a condition that begins gradually and becomes progressively worse. STS, conversely, can occur following the exposure to a single traumatic event. "In contrast to burnout, (...) STS (compassion stress) can emerge suddenly with little warning" [16]. Additionally, and different to burnout, STS "is associated with a sense of helplessness and confusion and a greater sense of isolation from supporters" [20]; the symptoms are often disconnected from real causes, and yet there is a faster recovery rate.

Given the commonalities of the terms CF, VT and STS, the link between secondary traumatic stress and PTSD, and the fact that secondary traumatic stress is often used by other authors when referring to compassion fatigue and/or vicarious traumatization we use the term secondary traumatic stress in the current study $[15,24,29]$. The problem of burnout among the mental health professionals has been examined in a variety of studies, but predominantly in conventional settings. A significant body of research has documented the prevalence of burnout among nurses [30-33] and among mental health professionals including social workers, psychologists, case managers, and occupational therapists [34-37]. Differential rates of burnout have been reported among human service providers who work with clients with physical disabilities, the economically disadvantaged [38], and sex offenders [39]. The results reveal that setting and/or type of clients seem to play role in the rates and severity of burnout observed.

There is a limited amount of literature focusing on CF among nurses [40-42]. The results of survey data collected from 280 Canadian mental health professions (certified clinical counselors, psychologists, psychiatrists, social workers, community agency counselors, and other individuals) who were identified as trauma therapists concluded that therapists with past personal histories of trauma who worked in community agencies with high caseloads of traumatized clients had increased levels of CF [43].There are several studies on the relationship between CF and burnout among mental health professionals in conventional settings [44-47]. The results of the study [48] revealed significant positive correlations between VT, STS and BO in the sample of sexual assault and domestic violence agency staff and volunteers. In the study by the relationship of BO, CF, and STS to personal/environmental characteristics, coping mechanisms, and exposure to traumatic events was explored in trauma nurses [49]. The study provides a systematic review of the empirical evidence for associations between job burnout and secondary traumatic stress (STS) among professionals working with trauma survivors, indirectly exposed to traumatic material [50]. This review yielded 41 original studies, analyzing data from a total of 8,256 workers and their meta-analysis indicated that associations between job burnout and STS were strong.

Researches examining the problem of burnout and/or STS among correctional mental health professionals are rather rare. However, the nature of the correctional setting, paired with the level of intimacy, engagement, and interaction between correctional officers as well as psychologists and those placed in their care, would seemingly render them equally vulnerable to experiences of secondary trauma. Within the past two decades, researchers have examined several occupational issues related to correctional workers. However, the major part of these researches has focused primarily on correctional officers. For example, the literature review presents an overview of occupational stress and burnout in correctional institutions, based on 43 investigations from 9 countries [51]. It appears that the most notable stressors for correctional officers are role problems, work overload, demanding social contacts (with prisoners, colleagues, and supervisors), and poor social status. Another literature review has revealed that most frequently reported predictors of burnout among prison staff were personality variables, stress, role ambiguity, role conflict, work load, understaffing, lack of environmental control, lack of participation in decision-making, 
inmate contact, and confrontations with inmates and job danger [2]. In addition, several previous researchers have reported that physical conditions of prisons were significant in predicting burnout [52]. The results of the study revealed several variables as correlates of vicarious trauma and secondary traumatic stress among correctional officers [53]. These included job satisfaction, number of hours in direct contact with inmates, personal support, organizational support, level of perceived job related danger, number of violent incidents observed, and number of times personally assaulted by an inmate.

Several studies have been made to examine the effects of prison work on guards and their families [54-56]. Among their findings were that correctional officers changed in the ways they perceived danger, developed rigid external structure to reduce internal anxiety, became desensitized to emotional stimuli, and brought their coping mechanisms and prison culture into their homes.

We found only few studies revealing that correctional psychologists were dissatisfied with various aspects of their jobs, such as administrative responsibilities, limited opportunities for advancement, and lack of influence with decision-making $[3,4,7,57]$. One recent study indicated that correctional psychologists do, in fact, experienced higher levels of burnout compared with psychologists who work in other settings [58]. Although the historical focus of burnout and STS researches has been on variables that are typically outside of the control of the provider who is experiencing burnout or STS (e.g., occupational and organizational factors), it is likely that individual difference factors also play an important role in the development of burnout and STS [59].

Indeed, the personality-burnout relationship has received attention in several metaanalyses. Such personality variables as locus of control [60], positive affectivity and negative affectivity [61], self-efficacy, self-esteem, locus of control, emotional stability, extraversion, conscientiousness, positive affectivity, negative affectivity, optimism, proactive personality were examined as a predictor of burnout [62]. A meta-analysis by examined the relationships between employee personality (core self-evaluations (CSE); characteristics of the Five-Factor Model of personality traits; positive and negative affectivity; optimism; proactive personality hardiness; and Type a Personality) and the sub-dimensions of burnout [63]. Five Factor Model of Personality ("Big Five") is most often used to evaluate the associations between personality and burnout. However the results of these studies are rather contradictory. The only variable that is positively associated with burnout in all studies is neuroticism. Even the variable of extraversion demonstrated inconsistent results. Some studies reveal the negative relations between extraversion and burnout, while others demonstrate significant positive association between extraversion and burnout. Other three variables of the "Big Five" namely open to experience, agreeableness and conscientiousness demonstrate even more contradictive relations with burnout [64].

The results of several studies indicated that personality variables seem to have an important role in secondary traumatic stress's process. One exploratory study Badger examined the predictive contribution of empathy, emotional separation (or differentiation), occupational stress and social support to secondary traumatic stress and cognitive disturbance in hospital social workers [65]. The empirical study [66] explores the process of secondary traumatic stress among sanitary professional, focusing on the contribution and the degree of relevance of personality variables, such as comprehensibility, challenge, sense of humor and empathy. The study of [67] assessed STS, compassion satisfaction (CS) and potential personality-related buffers of attachment orientations, spirituality, and sense of coherence among Israeli residential child-care workers working in residential treatment facilities for children and youth at risk as compared to educational boarding schools workers. Results revealed significant 
positive correlation between STS and BO, as well as between STS, BO and attachmentanxiety/attachment-avoidance. Spirituality and sense of coherence were negatively related to STS and BO. Another study [68] found that in the group of residential childcare workers employed in acute and long-term facilities for disturbed and traumatized children the best predictor for STS was BO followed by feeling of being supported outside work and self-care practices such as reading for pleasure.

We found only one study investigating the psychological predictors of burnout among correctional mental health professionals [69]. This study focused on the experience of burnout among a sample of correctional mental health professionals and examined the relationship of a linear combination of optimism, work family conflict, and attitudes toward prisoners with such dispositions as "Negative Experience of Work" and "Positive Experience of Work".In our study we focus on the psychological characteristics as they manifest in two personality resources: world-view model (benevolence of the world, meaningfulness of the world, and worthiness of the self)) and locus of control (general locus of control, loci of control on achievements, on failures, on family, on work, on interpersonal relations, on health/illness).

One way to understand individuals' reactions to traumatic events is to consider their most basic assumptions about themselves and the world, particularly regarding their vulnerability to negative events. "A positive or negative appraisal of a stressor differentially affects the stress process" [70]. According to [71-73], we all maintain fundamental beliefs or personal theories about the self and the world that are developed and refined throughout a lifetime of experiences. These basic assumptions center on a perspective of safety and well-being and include: (a) a belief in personal invulnerability (Benevolence of the World); (b) a perception of the world as meaningful and sensible (Meaningfulness of the World); and (c) a view of the self in a positive light (Worthiness of the Self).

Researches argue that more positive core beliefs may serve as a protective factor against the development of posttraumatic symptoms. The WAS has been widely used to explain the psychological reactions to traumatic events such as combat-related stress [74], torture [75], and natural disaster [76]. One recent study [77] found that police academy cadets with a greater sense of self-worth and stronger beliefs about the benevolence of the world experienced fewer symptoms of PTSD after two years of service, suggesting that an officer's world assumptions can act as a buffer against the deleterious effects of exposure to trauma. Many studies have found that people with posttraumatic stress symptoms have more negative world assumptions than people without such reactions (e.g., [78-80]). For example, low self-worth has been strongly related to high levels of posttraumatic stress symptoms across different types of traumatic experiences (e.g., $[74,78,79,81,82])$. Low levels of assumption of benevolence of the world or other people have been related to greater posttraumatic stress symptoms in the studies (e.g., [74,77-80,82] ).

Assumptions such as meaningfulness, justice, luck, randomness, controllability, and self-control have, to a lesser degree, been related to posttraumatic stress symptoms (e.g., $[74,77,81-84]$ ). Figley claims that compassion fatigue is related to the cognitive schema (social and interpersonal perceptions or morale) of the counselor and therefore related to vicarious traumatization [16]. A study by [85], based on a sample of family therapists, found that there was a significant correlation between measures of cognitive schemas and measures of STS.

In our study we hypothesize that the way in which correctional psychologist construes an event in terms of its consistency with his or her most basic assumptions about the self and the world can be an important determinant of his or her functioning, ability to cope with burnout and STS. External/internal locus of control is among the 
most often cited predictors of burnout (e.g. [60]). Locus of control is based on the social learning theory of Rotter and the attribution theory of Heider [86]. Rotter's social learning theory distinguishes between individuals who have an internal locus of control (belief that reinforcement of their behavior is dependent on own achievements, abilities, and commitment) and those who have an external locus of control, that is, believing that luck, fate, and influential people are responsible for reinforcement of their behavior.

Researches by [87-90] indicated a positive correlation between internal locus of control and psychological well-being. Individuals who are psychologically well have an enduring sense of personal control [91]. Along the same line, Young stated that the locus of control serves as a mediator between stress and psychological well-being, concluding that an internal locus of control positively influences levels of satisfaction and quality of life [92]. In our study we hypothesize that the internal locus of control in correctional psychologist can be an important determinant of his or her functioning, ability to cope with burnout and STS. The aim of the present study was to examine associations between secondary traumatic stress (ST), job burnout (BO) and several psychological variables such as world assumptions and locus of control in correctional psychologists.

\section{METHOD}

\section{Participants}

Thirty correctional departments across the Russia were contacted to elicit their interest in employee participation. The twenty two correctional settings that approved the current research study allowed the researcher access to their employees via e-mail or mail. After obtaining approval from the Ethical Committee of I.I. Mechnikov NorthWest State Medical University, St.-Petersburg, potential participants were initially contacted with a cover letter (either in electronic or paper format) to introduce the researcher, to explain the nature, purpose, and importance of the study and what participation in the study would entail, and to contact information for the primary researcher if they had any questions. If potential participants chose to participate, they were then presented with an opportunity to give their informed consent before beginning the survey.

This study utilized information provided by 87 currently practicing correctional mental health providers (psychologists) in the correctional settings in St.-Petersburg, Belgorod, Vladimir, Kaluga, Ryazan, etc. The sample included 51 men, 36 women. The mean age of participants was $34.9 \pm 6.9$ (ranging from 25 to 48 years). Participants reported working a mean of $6.23 \pm 3.5$ years (ranging from 3 months to 15 years) in a correctional setting.

\section{Measures}

Participants were sent a packet or an e-mail that contained a cover letter, an informed consent document, a demographic questionnaire, the Maslach Burnout Inventory-Human Services Survey (MBI-HSS) [93], Secondary Traumatic Stress Scale (STSS) [94], World Assumptions Scale [72] and Locus of control Scale (LOC) [96]. All surveys were completed anonymously. The measures utilized in the study included a demographic questionnaire that gathered data such as age, gender, number of years as correctional psychologist.Subjects were assessed with measures listed below. Russianvalidated translations of all measures were used.

\section{Maslach Burnout Inventory-Human Services Survey (MBI-HSS)}

The MBI-HSS is a 22-item measure consisting of three scales designed to assess emotional exhaustion (EE), depersonalization (D), and lack of personal accomplishment (PA) [93]. In the original versions of MBI higher mean scores correspond to higher 
degrees of burnout for the EE and D subscales, and lower mean scores for PA subscale correspond to higher degrees of experienced burnout. In our study we followed the approach presented in several studies (e.g. [96]) that inversed the scores of PA subscale (reduced personal accomplishment-RPA) in order to compare scores in all three subscales and in order to count the total MBI score. Individuals endorse the frequency with which each item occurs on a 7-point Likert scale ranging from never (0) to every day (6). Storm and Rothmann reported alpha coefficients of 0.88 (Exhaustion), 0.78 (Cynicism) and 0.79 (Professional Efficacy) in a sample of police officers [97]. Distributions of scores in subscales in Russian sample are looking as follows: emotional exhaustion- 0-15 (low), 16-24 (medium), >25 (high); depersonalization - 0-5 (low), 6-10 (medium), >11 (high); reduced personal accomplishment - 0-11 (low), 12-17 (medium), >18 (high) [99]. Score of 54 was accepted as cut-off between low/medium and high levels of burnout.

Secondary Traumatic Stress Scale (STSS) is a 17-item instrument designed to measure work-related secondary traumatic stress in human service professionals [94]. STSS is comprised of three subscales (Intrusion, Avoidance, and Arousal) that are congruent with the PTSD symptom clusters as delineated in the DSM-IV-TR [98]. Respondents indicate how frequently they experienced each of 17 symptoms during the previous week using a five-choice, Likert-type response format ranging from never (1) to very often (6).Means and standard deviations for the STSS and its subscales were as follows: Full STSS $(M=29.49, S D=10.76)$, Intrusion $(M=8.11, S D=3.03)$, Avoidance $(M=12.49, S D=5.00)$, and Arousal $(M=8.89, S D=3.57)$. As reported by [99], the internal consistency reliability of the Russian version of STSS, as measured with Cronbach's coefficient alpha, was 0.89 for intrusion, 0.95 for avoidance, and 0.91 for arousal. Bride recommends individuals with a score of 38 or higher on the STSS Total Score are considered to have PTSD due to secondary traumatic stress [100].

\section{World Assumptions Scale}

The World Assumptions Scale [72] is a 32-item self-report measure of basic cognitive assumptions about the self and the world. Respondents indicated their agreement or disagreement with each item on a 6-point Likert scale ranging from strongly disagree (1) to strongly agree (6), and average scores for each subscale were calculated. Initial validation on the WAS revealed adequate reliabilities (alpha=0.67-0.78), with three of the eight subscales (Perceived Selfworth, Chance, and Benevolence of the World) emerging as significant discriminators of victim and non-victim status. In our study we used combinations of the eight subscales [101] resulting in three secondary dimensions: benevolence of the world (sum of benevolence of people and benevolence of the world scores), meaningfulness (sum of justice, randomness, and control scores), and self-worth (sum of self-worth, luck, and self-control).

The revised 44-item Locus of Control Inventory Rean was developed to measure generalized expectancies for internal versus external control of reinforcement [95]. Seven locus of control subscales of the inventory were used in this study: general, on achievements, on failure, on family relationships, on work, on interpersonal relationships and on health/illness. The answers are based on six-point Likert scale ranged from +3 (agree strongly) to -3 (disagree strongly). The raw scores are converted into sten scores. Low scores ( 1 to 5 stens) indicate an external control while high scores (6 to 10 stens) indicate internal control.

\section{STATISTICAL ANALYSIS}

Statistical analyses of the obtained data were carried out using SPSS 16.0 for Windows. Prior to completing analyses, all the obtained data were checked for normality (Kolmogorov-Smirnov test), homogeneity of variances (Levene's test), sphericity (Mauchly's test of sphericity) and equality of the covariance matrixes across 
groups (Box's M-test). A one-way ANOVA was used for between-group comparisons. Bivariate, two-tailed nonparametric (Spearman) correlations were used to investigate the strength of the associations between variables. A one-way ANOVA was used for between-group comparisons.

After baseline assessment data analysis was presented in three stages. First, all subjects in our sample were divided into two groups in accordance with burnout level (group 1: low and medium and group 2: high levels of burnout). Then we performed oneway ANOVA with burnout groups as a factor regarding STS components, world-view model and locus of control (general locus of control, loci of control on achievements, on failures, on family, on work, on interpersonal relations, on health/illness). Second, all subjects in our sample were divided into two groups in accordance with STS level (group 1: low and group 2: high levels of STS). Then we performed one-way ANOVA with STS groups a factor to examine differences between the groups regarding BO components, world assumptions components and locus of control components. Third, in order to examine the relationship between the study variables, we performed a series of Spearman correlation analyses.

\section{RESULTS}

In the first set of analysis two groups of subjects were formed based on the results from the MBI-GS survey: group 1 with low and medium $(n=45)$ and group 2 with high levels of burnout $(n=42)$. After groups were formed, the results of one-way ANOVAs with group as a factor in entire sample indicated no differences in burnout level due to age $(F(1,86)=1.56, p=0.22)$, gender $(F(1,86)=1.06, p=0.31)$, or number of years in corrections $(F(1,86)=0.85, p=0.36)$. However, the ANOVAs demonstrated that subjects of group 1 (low and medium burnout) compared with the subjects of group 2 (high burnout) had significantly different levels not only of burnout and its components but also of secondary traumatic stress (except for intrusion) as well as of major personality variables, except for meaningfulness of the world, locus of control on family and interpersonal relations (Table 1).

In the second set of analysis two groups of subjects were formed based on the results from the Secondary Traumatic Stress Scale (STSS): group 1 with low ( $\mathrm{n}=57$ ) and group 2 with high levels of secondary traumatic stress $(n=30)$. After groups were formed, the results of one-way ANOVAs with group as a factor in entire sample indicated no differences in STS level due to age $(F(1,86)=0.27, p=0.61)$ and gender $(F(1,86)=2.46$, $p=0.12$ ). However, in contrast to the results of the fist set of analysis, the ANOVAs demonstrated that subjects of group 1 (low STS) compared with the subjects of group 2 (high STS) have significantly different levels only of STS and its components, number of years in corrections, depersonalization, total MBI score and benevolence of world (Table 2). The results reveal no differences in any other variables under consideration in two groups.

The third set of analysis examined cross-sectional associations among number of years in corrections, emotional exhaustion, depersonalization, reduced personal accomplishments, MBI (total score), intrusion, avoidance, arousal, STS (total score), benevolence of world, meaningfulness, self-worthiness, general locus of control, locus of control on achievements, on failures, on family, on work, on interpersonal relationships, on health/illness. A Spearman's two-tailed correlation was run to determine the relationships between the scales. The results are presented in Table 3.

The results revealed significant positive associations between the number of years in corrections and STSS total score, as well as all three STSS subscales: intrusion, avoidance and arousal. However, no significant associations were found between the number of years in corrections and MBI scores, except for depersonalization, as well as with any subscales of WAS and Locus of control subscales, except for general 
Table 1: Average scores of psychological variables in groups 1 (with low and medium burnout levels) and 2 (with high burnout level).

\begin{tabular}{|c|c|c|c|c|}
\hline Variables & $\begin{array}{c}\text { Group } 1 \\
\mathrm{~N}=45 \\
\mathrm{M}(\mathrm{SD})\end{array}$ & $\begin{array}{c}\text { Group } 2 \\
\mathrm{~N}=42 \\
\mathrm{M}(\mathrm{SD})\end{array}$ & $\begin{array}{l}\text { ANOVA } \\
F(1,86)\end{array}$ & $\mathbf{P}$ \\
\hline 1. Number of years in corrections & $5.6(3.9)$ & $6.3(2.9)$ & 0.85 & 0.359 \\
\hline 2. Emotional exhaustion (EE) & $21.0(2.8)$ & $26.7(2.6)$ & 96.2 & 0.000 \\
\hline 3. Depersonalization (D) & $9.1(2.1)$ & $14.3(2.8)$ & 93.6 & 0.000 \\
\hline $\begin{array}{l}\text { 4. Reduced personal } \\
\text { accomplishments (RPA) }\end{array}$ & $13.1(3.9)$ & 16.7(3.8) & 19.2 & 0.000 \\
\hline 5. MBI (total score) & $43.2(6.8)$ & $57.7(3.5)$ & 153.8 & 0.000 \\
\hline 6. Intrusion (I) & $10.8(1.9)$ & $11.1(2.9)$ & 0.27 & 0.608 \\
\hline 7. Avoidance (AV) & $12.5(2.5)$ & 15.5.(3.7) & 19.3 & 0.000 \\
\hline 8. Arousal (AR) & 10.1(1.6) & $11.4(2.5)$ & 7.3 & 0.008 \\
\hline 9. STSS (total score) & $33.5(5.1)$ & $37.9(7.9)$ & 10.0 & 0.002 \\
\hline 10. Benevolence of world (BW) & $18.1(1.5)$ & $17.2(1.6)$ & 7.2 & 0.009 \\
\hline 11. Meaningfulness $(M)$ & $14.4(1.1)$ & $14.8(1.9)$ & 1.59 & 0.210 \\
\hline 12. Self worthiness (SW) & $17.5(.0)$ & $16.6(1.3)$ & 16.6 & 0.000 \\
\hline 13. General locus of control (LC) & $6.5(1.4)$ & $5.1(1.9)$ & 14.3 & 0.000 \\
\hline 14. LC on achievements & $6.9(1.7)$ & $5.9(1.8)$ & 7.2 & 0.009 \\
\hline 15. LC on failures & $6.4(1.6)$ & $5.1(2.1)$ & 11.3 & 0.001 \\
\hline 16. LC on family & $6.3(1.9)$ & $6.1(1.3)$ & 0.29 & 0.587 \\
\hline 17. LC on work & $5.2(1.5)$ & $4.3(1.9)$ & 6.5 & 0.013 \\
\hline 18. LC on interpersonal & $6.9(.7)$ & $6.6(1.7)$ & 1.7 & 0.200 \\
\hline 19. LC on health/illness & $5.8(1.5)$ & $4.4(1.8)$ & 14.5 & 0.000 \\
\hline
\end{tabular}

Table 2: Average scores of psychological variables in groups 1 (with low STS) and 2 (with high STS).

\begin{tabular}{|c|c|c|c|c|}
\hline Variables & $\begin{array}{c}\text { Group } 1 \\
\mathrm{~N}=57 \\
\mathrm{M}(\mathrm{SD})\end{array}$ & $\begin{array}{c}\text { Group } 2 \\
\mathrm{~N}=30 \\
\mathrm{M}(\mathrm{SD})\end{array}$ & $\begin{array}{l}\text { ANOVA } \\
F(1,86)\end{array}$ & $\mathbf{P}$ \\
\hline 1. Number of years in corrections & $5.4(3.5)$ & $7.0(3.0)$ & 4.4 & 0.039 \\
\hline 2. Emotional exhaustion (EE) & $23.6(4.3)$ & $24.0(3.1)$ & .17 & 0.681 \\
\hline 3. Depersonalization (D) & $10.3(2.9)$ & $14.2(3.2)$ & 32.5 & 0.000 \\
\hline $\begin{array}{l}\text { 4. Reduced personal } \\
\text { accomplishments (RPA) }\end{array}$ & $14.7(4.8)$ & $15.1(3.2)$ & 0.19 & 0.668 \\
\hline 5. MBI (total score) & $48.6(10.2)$ & $53.3(5.4)$ & 5.6 & 0.020 \\
\hline 6. Intrusion (I) & $9.6(1.7)$ & $13.5(1.2)$ & 120.4 & 0.000 \\
\hline 7. Avoidance (AV) & $12.3(2.6)$ & $17.1(2.6)$ & 65.4 & 0.000 \\
\hline 8. Arousal (AR) & $9.8(1.7)$ & $12.5(1.8)$ & 45.6 & 0.000 \\
\hline 9. STSS (total score) & $31.7(4.1)$ & $43.1(4.6)$ & 140.9 & 0.000 \\
\hline 10. Benevolence of world (BW) & $18.1(1.6)$ & $16.8(1.1)$ & 16.8 & 0.000 \\
\hline 11. Meaningfulness (M) & $14.7(1.7)$ & $14.4(1.2)$ & 0.52 & 0.475 \\
\hline 12. Self worthiness (SW) & $17.2(1.1)$ & $16.8(1.3)$ & 2.5 & 0.116 \\
\hline 13. General locus of control (LC) & $5.9(1.9)$ & $5.7(1.6)$ & 0.35 & 0.555 \\
\hline 14. LC on achievements & $6.6(1.7)$ & $6.2(2.0)$ & 0.87 & 0.354 \\
\hline 15. LC on failures & $5.6(2.1)$ & $6.0(1.6)$ & 0.69 & 0.406 \\
\hline 16. LC on family & $6.4(1.5)$ & $5.9(1.8)$ & 2.1 & 0.155 \\
\hline 17. LC on work & $4.8(1.8)$ & $4.6(1.7)$ & 0.38 & 0.537 \\
\hline 18. LC on interpersonal & $6.8(1.3)$ & $6.7(1.3)$ & 0.09 & 0.764 \\
\hline 19. LC on health/illness & $5.3(1.9)$ & $4.9(1.7)$ & 0.79 & 0.376 \\
\hline
\end{tabular}

locus of control and locus of control on family. MBI subscales were associated with STSS subscales as following. Emotional exhaustion was significantly positively associated with avoidance, arousal and total STSS score, but not with intrusion. Depersonalization was significantly positively associated with all three STSS subscales: intrusion, avoidance, and arousal and with total STSS score as well. Reduced personal 


\begin{tabular}{|c|c|c|c|c|c|c|c|c|c|}
\hline Variables & Years & EE & D & RPA & MBI & I & AV & AR & STSS \\
\hline $\begin{array}{l}\text { 1. Number of years in } \\
\text { corrections (Years) }\end{array}$ & - & & & & & & & & \\
\hline $\begin{array}{l}\text { 2. Emotional } \\
\text { Exhaustion (EE) }\end{array}$ & 0.13 & - & & & & & & & \\
\hline 3. Depersonalization (D) & $0.22^{\star}$ & $0.62^{\star \star}$ & - & & & & & & \\
\hline $\begin{array}{l}\text { 4. Reduced personal } \\
\text { accomplishments (RPA) }\end{array}$ & -0.08 & $0.34^{\star \star}$ & 0.16 & - & & & & & \\
\hline 5. MBI (total score) & 0.15 & $0.88^{\star *}$ & $0.74^{\star \star}$ & $0.62^{\star \star}$ & - & & & & \\
\hline 6. Intrusion (I) & $0.27^{*}$ & -0.03 & $0.43^{\star \star}$ & $-0.24^{\star}$ & 0.04 & - & & & \\
\hline 7. Avoidance (AV) & $0.44^{\star \star}$ & $0.36^{\star \star}$ & $0.57^{\star \star}$ & $0.28^{\star \star}$ & $0.49 \star \star$ & $0.45^{\star \star}$ & - & & \\
\hline 8. Arousal (AR) & $0.39^{\star \star}$ & $0.41^{\star \star}$ & $0.56^{\star \star}$ & -0.12 & $0.34^{\star \star}$ & $0.51^{\star \star}$ & $0.69 * \star$ & - & \\
\hline 9. STSS (total score) & $0.46^{\star \star}$ & $0.30 * *$ & $0.61^{\star \star}$ & 0.04 & $0.38^{\star \star}$ & $0.75^{\star \star}$ & $0.89 * *$ & 0.84 ** & - \\
\hline $\begin{array}{l}\text { 10. Benevolence of world } \\
\text { (BW) }\end{array}$ & -0.15 & -0.11 & $-0.32^{\star \star}$ & $-0.38^{\star *}$ & $-0.33^{\star \star}$ & $-0.33^{\star}$ & $-0.49^{\star *}$ & -0.17 & $-0.46^{\star \star}$ \\
\hline 11. Meaningfulness (M) & -0.17 & -0.09 & 0.10 & -0.08 & 0.03 & -0.07 & -0.18 & $-0.30^{\star}$ & $-0.24^{*}$ \\
\hline 12. Self worthiness (SW) & 0.09 & $-0.43^{\star \star}$ & $-0.35^{\star \star}$ & $-0.32^{\star \star}$ & $-0.48^{\star \star}$ & -0.01 & $-0.22^{\star}$ & -0.01 & -0.17 \\
\hline $\begin{array}{l}\text { 13. General locus of control } \\
\text { (LC) }\end{array}$ & $-0.22^{*}$ & $-0.39 * *$ & $-0.36^{\star *}$ & -0.12 & $-0.39 * *$ & $-0.24^{*}$ & -0.05 & $-0.23^{\star}$ & -0.21 \\
\hline 14. LC on achievements & -0.16 & $-0.47^{\star *}$ & $-0.33^{\star *}$ & $-0.31^{* *}$ & $-0.46^{\star *}$ & -0.11 & -0.12 & -0.19 & -0.20 \\
\hline 15. LC on failures & -0.12 & $-0.37^{\star \star}$ & $-0.33^{\star *}$ & 0.02 & $-0.34^{\star \star}$ & -0.11 & 0.05 & $-0.23^{\star}$ & -.09 \\
\hline 16. LC on family & $-0.22^{*}$ & -0.19 & -0.16 & -0.08 & -0.18 & -0.21 & -0.13 & $-0.33^{\star \star}$ & $-0.27^{\star}$ \\
\hline 17. LC on work & -0.09 & $-0.21^{*}$ & $-0.21^{*}$ & -0.03 & -0.19 & -0.13 & 0.09 & 0.12 & -0.05 \\
\hline 18. LC on interpersonal & 0.05 & -0.20 & -0.16 & 0.13 & -0.14 & $-0.22^{*}$ & 0.14 & -0.02 & -0.05 \\
\hline 19. LC on health/illness & -0.16 & -0.16 & $-0.46^{\star *}$ & -0.11 & -0.29 ** & $-0.27^{*}$ & -0.13 & $-0.21^{*}$ & $-0.25^{\star}$ \\
\hline
\end{tabular}

accomplishments were significantly positively associated with avoidance, significantly negatively with intrusion and were not related to arousal and total STSS score. MBI total score was significantly positively associated with total STSS score, avoidance and arousal but not with intrusion.

MBI total score was significantly negatively associated with benevolence of world, self- worthiness, and general locus of control, locus of control on achievements, on failures and on health/illness. No associations were found between MBI total score and meaningfulness, locus of control on family, work and interpersonal relations. STSS total score was significantly negatively associated with benevolence of world, meaningfulness, locus of control on family and on health/illness. No associations were found between STSS total score and self- worthiness, general locus of control, locus of control on achievements, on failures, work and interpersonal relations. While in our sample all subscales of Locus of Control Inventory demonstrated significant positive correlations, a significant positive association was determined only between the WAS benevolence of world scale and the WAS self worth scale.

\section{DISCUSSION}

The results of our study reveal that burnout and secondary traumatic stress in correctional psychologists are significantly positively related and thus may be exacerbated by each other. Our results are supported by the results of several other studies in the field (e.g. [48,49]). Although, the provided in our study statistical analysis does not allow to do any conclusions about causal relationships between burnout and STS, the unexpected result of significant negative association between reduced personal accomplishments and intrusion let us hypothesize that some aspects of burnout could be regarded as protective factor a against the development of secondary traumatic stress. The line of our arguments is based on the idea proposed by [16] that the caregiver's level of empathy with the traumatized individual plays a significant role 
(or even could be regarded as the main mechanism) in the transmission of traumatic stress from one individual to another. Thus if the caregiver's level of empathy is decreasing due to burnout then his/her vulnerability to secondary traumatic stress can also decrease.

In our sample of correctional psychologists BO is significantly negatively associated with WAS benevolence scale and the WAS self worth scale and STS is significantly negatively associated with WAS benevolence scale and the WAS meaningfulness scale. Our results on WAS components and their associations with BO and STS were partly supported by the results [102]. They demonstrated a significant positive association between the WAS self worth scale and the WAS benevolence scale and the WAS self worth scale and the WAS meaningfulness scale. Also these results revealed a significant negative relationship between the WAS benevolence scale and the STS scale. Also, our results on associations between WAS components and STS are consistent with several other studies. For example, Foa, Ehlers, et al., reported significant negative correlations between both trauma-related cognitions and PTSD severity and the WAS dimensions of self-worth [79], luck, self-control, and benevolence of world; benevolence of people was only associated with trauma-related cognitions. A very similar pattern of significant correlations was also reported by [82] who reported that self-worth, luck, benevolence of people, and benevolence of world were negatively related to PTSD severity. Dekel, Solomon, et al found that current PTSD status of Israeli veterans was associated1 only with scores for benevolence of people and self-worth [103].

Locus of control and its components in our sample are negatively associated with BO, but not with STS. Our results on BO and locus of control are corroborated by several other studies (e.g. [60,62]). Other important results in our study were obtained from the comparison of groups with low/medium, and high levels of BO and low and high levels of STS tables 1 and 2. These results revealed that groups with different levels of BO have also different levels of STS (avoidance, arousal and total) as well as of WAS and LC scales. Comparison of groups with different levels of STS revealed that they are different only in BO (depersonalization and total) and WAS benevolence scale.

One possible explanation of these phenomenons was proposed in studies by $[79,104,105]$ who proposed a curvilinear relation between beliefs and PTSD symptoms. PTSD may develop when rigid negative schemas are confirmed, or when rigid positive schemas are violated. Thus, Foa suggest that the presence of rigid concepts about self and the world (positive or negative) renders individuals vulnerable to develop PTSD [79]. In contrast, people with more flexible beliefs about safety will be most likely to recover after a traumatic event. Although it can be argued that people with negative schemas already suffer from some kind of psychopathology, Foa and Riggs suggest that these negative schemas may have resided in long-term memory with high activation thresholds and therefore may not have resulted in severe psychopathology [106].

The same considerations maybe correct for the construct of locus of control. Hipps and Malpin measured the internal locus of control of middle-school principals under the stress of threatened unemployment [107]. They found that the higher these principals scored on internal locus of control, the higher they scored on the MBI. This result suggests that locus of control, as a construct indicating general expectancy, is not the determinant of burnout. Instead, the capability to modify one's perceptions of control to fit situation demands is more important [108]. In other words, what can prevent burnout is not an internal locus of control, but an accurate perception of controllability of the situation, and an appropriate appraisal and matched coping strategies.

\section{Limitations of the Study and Future Research Directions}

Study limitations include a small sample size and the differences in employment classification across correction settings. For example, some correctional mental health 
professionals are also considered correctional workers and expected to assist with correctional responsibilities, whereas others are not. The small sample size could prevent generalizing the findings to the population of correctional mental health professionals. During the data collection process, it became apparent that employee classification varied by location, with some locations labeling mental health providers "counselors" and other states labeling them "psychological services specialists." This variability may have caused ineligible employees to receive the survey packet and prevented eligible employees from receiving the survey packet.

The main future direction of our research is to construct nonlinear model of burnout, identify its parameters and make the validation of the model. This model is based on the method of response functions described in many articles (e.g., [109]) and monograph [110] Although some studies (e.g. [68]) reveal that BO is the best predictor for STS our future study is based on another conceptual framework. The key factor that differentiates STS and burnout lies in the cause of the symptoms. Symptoms of STS occur as a direct result of hearing emotionally shocking material from clients, whereas burnout can occur as a result of work with any client group, but in response to stressors resulting from the organizational environment and/or lack of personal resources. STS includes, but is not limited to, countertransference. Both concepts involve an individual's reaction to another's life experiences. Countertransference has been defined as the therapist's unconscious responses toward a client. STS is an outcome or risk that is related to engaging empathically with another's traumatic material. Empathizing with a traumatized client helps the worker to understand the client's experience of being traumatized, but in the process the worker may be traumatized as well. Thus basing on the idea proposed by [16] that if the caregiver's level of empathy is decreasing due to burnout then his/her vulnerability to secondary traumatic stress can also decrease we suppose that it is unlikely that low level of burnout can predict low level of STS.

Vice versa we hypothesize that lower levels of STS and optimal levels of WA and LC scales predict lower burnout in correctional psychologists. Based on our theoretical framework and review of the literature [79,104,105,107,108] we reasoned that correctional psychologists who experience a lower degree of STS in their work and optimal levels of WA and LC would also experience more positive work environment or person-job match in the areas of work life, which would decrease job burnout. Those correctional psychologists who experience higher STS in their work would perceive their work environment more negatively and encounter lower person-job match, which in turn contributes to greater job burnout.

Then the model of burnout (BOmodel) is looking as follows:

$$
\begin{aligned}
& B O_{\text {mod }}=B O_{\max } \cdot \exp \left(-F_{s t}\right) \\
& F_{s t}=f_{1}(S T S) \cdot f_{2}(B W) \cdot f_{3}(M) \cdot f_{4}(S W) \cdot f_{5}(L C) \\
& f_{1}(S T S)=1.0-b_{1}\left(1.0-\exp \left(-c_{1} \cdot S T S\right)\right)^{d_{1}}, \\
& f_{j}\left(x_{j}\right)=\alpha_{j}\left(x^{b_{j}} \cdot \exp \left(-c_{j} \cdot\left(\frac{x}{x_{\max }-x}\right)^{\gamma_{j}}\right), j=2,3,4,5\right.
\end{aligned}
$$

where $B O_{\bmod }, B O_{\max }$ are the actual values of $\mathrm{BO}$ total score resulted from the MBI-HSS Survey and maximum possible score, STS are the scores of STSS total scale, $B W$ are the scores of Benevolence of the World subscale of WAS, $M$ are the scores of Meaningfulness subscale of WAS scale, $S W$ are the scores of Self worthiness subscale of WAS scale, $L C$ is General Locus of Control subscale of LC scale, $F_{s}, f_{j}$ are the generalized and partial response functions respectively, $\alpha_{j}, b_{j}, c_{j}, d_{j}, \gamma_{j}$ are parameters for evaluation, $j=1, . ., 5$. 
Translating these mathematical symbols into words, these nonlinear equations state that the actual level of burnout is increasing with the increasing of secondary traumatic stress and is decreasing with the increasing of such psychological variables as benevolence of the world, meaningfulness of the world, worthiness of the self and general locus of control until the optimal point of each variable. After the optimal points are achieved the level of $\mathrm{BO}$ is starting to increase with the increasing of the psychological variables under consideration.

\section{REFERENCES}

1. Hawk, Kathleen M. Personal reflections on a career in correctional psychology. Professional Psychology. Research and Practice. 1997; 28: 335-337. Ref.: https://goo.gl/IE9VYW

2. Senter A. Correctional psychologist burnout, job satisfaction and life satisfaction. 2006. Ref.: https://goo.gl/meQYXg

3. Boothby JL, Clements CB. Job satisfaction of correctional psychologists: Implications for recruitment and retention. Professional Psychology: Research and Practice. 2002; 33: 310-315. Ref.: https://goo.gl/AMHfYX

4. Boothby JL, Clements CB. A national survey of correctional psychologists. Criminal Justice and Behavior. 2000; 27: 716-732. Ref.: https://goo.gl/95ndeO

5. Thomas JF, Augustin D. Criminal justice and mental health systems: The new continuum of care system. Correctional mental health: From theory to best practice. 2011; 7-35. Ref.: https://goo.gl/gLXrf5

6. Powitzky RJ. Comparisons of correctional and community mental health service delivery models. Correctional mental health: From theory to best practice. 2011. Ref.: https://goo.gl/6ZU58D

7. Smith RR, Sabatino DA. Roles and functions of psychologists in American correctional institutions. Journal of Offender Rehabilitation. 1990; 16: 163-174. Ref.: https://goo.gl/XOSZyh

8. Richard R. The uncritical acceptance of risk assessment in forensic practice. Law and Human Behavior. 2000; 24: 595-605. Ref.: https://goo.gl/oiameg

9. Silberman M. The social origins of violence in the American prison. Violence and society: A reader. 2003; 347-364.

10. Haag AM. Ethical Dilemmas Faced by Correctional Psychologists in Canada. Criminal Justice and Behavior. 2006; 33: 93-109. Ref.: https://goo.gl/1jYIDZ

11. Freudenberger HJ. Staff burn-out. Journal of Social Issues. 1974; 30: 159-165. Ref.: https://goo.gl/IXe78n

12. Maslach C. Burnout: The cost of caring. Englewood Cliffs, NJ: Prentice Hall. 1982. Ref.: https://goo.gl/LySyj5

13. Maslach C, Jackson SE, Leiter MP, Schaufeli WB. Maslach burnout inventory, (3rd ed.), Menlo Park, CA: Mind Garden. 1981. Ref.: https://goo.gl/JeyvDV

14. McCann IL, Pearlman LA. Vicarious Traumatisation: A Framework for Understanding the Psychological Effects of Working with Victims. Journal of Traumatic Stress. 1990; 3: 131-149. Ref.: https://goo.gl/4m4Nio

15. Pearlman LA, Saakvitne KW. Trauma and the therapist: Countertransference and vicarious traumatization in psychotherapy with incest survivors. New York: Norton. 1995. Ref.: https://goo.gl/U6n7CU

16. Figley CR. Compassion Fatigue: Coping with Secondary Traumatic Stress Disorder in those who treat the traumatised. 1995; 12. Ref.: https://goo.gl/RbT1fv

17. Figley CR. Traumatic stress: The role of family and social support system. In C. R. Figley (Ed.), Trauma and its wake, Vol. II: Traumatic stress theory, research and intervention. 1986; 39-54.

18. Stamm BH. Secondary traumatic stress: Self-care issues for clinicians, researches and educators. 1995. Ref.: https://goo.gl/wdXNIh

19. Stamm BH. The ProQOL manual. The professional quality of life scale: Compassion satisfaction, burnout \& compassionfatigue/secondary trauma scales. 2005. https://goo.gl/Qrw7oo

20. Figley CR. Compassion fatigue: Psychotherapists' chronic lack of self care. Journal of Clinical Psychology. 2002; 58: 1433-1441. Ref.: https://goo.gl/Pbb49h 
21. Chrestman KR. Secondary exposure to trauma and self reported distress among therapists. In Stamm BH: Secondary traumatic stress: Self-care issues for clinicians, researchers, and educators. 1995; 29-36. Ref.: https://goo.gl/XjWF8k

22. Figley CR. Compassion fatigue: Toward a new understanding of the costs of caring. Secondary traumatic stress: Self-care issues for clinicians, researchers, \& educators. 1995; 3-28. Ref.: https://goo.gl/GXFd6b

23. Denhof MD, Spinaris CG, Morton GR. Occupational Stressors in Corrections Organizations: Types, Effects and Solutions. U.S. Department of Justice, National Institute of Corrections. 2014; Ref.: https://goo.gl/nYVD2E

24. Stamm BH. Work-related Secondary Traumatic Stress. The National Centre for Post-traumatic Stress Disorder: PTSD Research Quarterly. 1997; 8: 2-8. Ref.: https://goo.gl/TJv4ac

25. Stamm BH. The concise ProQOL manual. Pocatello, ID: ProQOL.org. 2010; Ref.: https://goo.gl/cpdWJe

26. Jenkins SR, Baird S. Secondary traumatic stress and vicarious trauma: A validation study. Journal of Traumatic Stress. 2002; 15: 423-432. Ref.: https://goo.gl/n7LSSh

27. Sabin-Farrell R, Turpin G. Vicarious traumatization: Implication for the mental health of health workers. Clinical Psychology Review. 2003; 23: 449-480. Ref.: https://goo.gl/JoQjaz

28. Salston MD, Figley CR. Secondary traumatic stress effects of working with survivors of criminal victimization. Journal of Traumatic Stress. 2003; 16: 167-174. Ref.: https://goo.gl/CO3VGM

29. Ortlepp K. Non-Professional Trauma Debriefers in the Workplace: Individual and Organisational Antecedents and consequences of their Experiences. 1998. Ref.: https://goo.gl/smfK1h

30. Aiken LH, Clarke SP, Sloane DM, Sochalski J, Silber JH. Hospital nurse staffing and patient mortality, nurse burnout, and job dissatisfaction. Journal of the American Medical Association. 2002; 288 1987-1993. Ref.: https://goo.gl/6w5wPE

31. Janssen PM, deJonge J, Bakker AB. Specific determinants of intrinsic work motivation, burnout and turnover intentions: A study among nurses. Journal of Advanced Nursing. 1999; 29: 1360 1369. Ref.: https://goo.gl/eXavxB

32. Laschinger HK, Shamian J, Thomson D. Impact of Magnet Hospital characteristics on nurses' perceptions of trust, burnout, quality of care, and work satisfaction. Nursing Economics. 2001; 19: 209-219. https://goo.gl/NuW9gK

33. Leiter MP, Maslach C. A mediation model of job burnout. Research companion to organizational health psychology. 2005; 544-564. Ref.: https://goo.gl/oEDI4n

34. Acker GM. Burnout among mental health care providers. Journal of Social Work. 2011; 1-16. Ref.: https://goo.gl/47WMBh

35. Lasalvia A, Bonetto C, Bertani M, Bissoli S, Cristfalo D, et al. Influence of perceived organizational factors on job burnout: Survey of community mental health staff. British Journal of Psychiatry. 2009; 195: 537-544. Ref.: https://goo.gl/uuddV5

36. Leiter MP, Harvie PL. Burnout among mental health workers: A review and a research agenda. International Journal of Social Psychiatry. 1996; 42: 90-101. Ref.: https://goo.gl/TL5rWI

37. Paris M, Hoge MA. Burnout in the mental health workforce: A review. The Journal of Behavioral Health Services \& Research. 2010; 37: 519-528. Ref.: https://goo.gl/xYbbo3

38. Gomez JS, Michaelis RC. An assessment of bumout in human service providers. The Journal of Rehabilitation. 1995; 61: 23-26. Ref.: https://goo.gl/4goHte

39. Shelby RA, Stoddart RM, Taylor KL. Factors contributing to levels of bumout among sex offender treatment providers. Journal of Interpersonal Violence. 2001; 16: 1205-1217. doi:10.1177/088626001016011006. Ref.: https://goo.gl/M7GHrS

40. Abendroth M, Flannery J. Predicting the risk of compassion fatigue: A study of hospice nurses. Journal of Hospice and Palliative Nursing. 2006; 8: 346-356. Ref.: https://goo.gl/lvC7bR

41. Austin W, Goble E, Leier B, Byrne P. Compassion fatigue: The experience of nurses. Ethics and Social Welfare. 2009; 3: 195-214. Ref.: https://goo.gl/67ao9c

42. Yoder EA. Compassion fatigue in nurses. Applied Nursing Research. 2010; 23: 191-197. Ref.: https://goo.gl/ClGGrf

43. Buchanan M, Anderson JO, Uhlemann MR, Horwitz E. Secondary traumatic stress: An investigation of Canadian mental health workers. 2006; 12: 272-281. Ref.: https://goo.gl/qm9WT7 
44. Alkema K, Linton JM, Davies R. A study of the relationship between self-care, compassion satisfaction, compassion fatigue, and burnout among hospice professionals. Journal of Social Work in End-Of-Life \& Palliative Care. 2008; 4: 101-119. Ref.: https://goo.gl/FEVZYo

45. Craig CD, Sprang G. Compassion satisfaction, compassion fatigue, and burnout in a national sample of trauma treatment therapists. Anxiety, Stress, \& Coping. 2010; 23: 319-339. Ref.: https://goo.gl/3QD6Bh

46. Murray M, Logan T, Simmons K, Kramer M B, Brown E, et al. Secondary traumatic stress, burnout, compassion fatigue and compassion satisfaction in trauma nurses. American Journal of Critical Care. 2009; 18: e1-e17. Ref.: https://goo.gl/JeOHT1

47. Sprang G, Clark JJ, Whitt-Woosley A. Compassion fatigue, compassion satisfaction, and burnout: Factors impacting a professional's quality of life. Journal of Loss and Trauma. 2007; 12: 259-280. Ref.: https://goo.gl/B3ssQK

48. Baird K, Kracen AC. Vicarious traumatization and secondary traumatic stress: A research synthesis. Counselling Psychology Quarterly. 2006; 19: 181-188. Ref.: https://goo.gl/HkeS2P

49. Hinderer KA, VonRueden KT, Friedmann E, McQuillan KA, Gilmore R, et al. Burnout, compassion fatigue, compassion satisfaction, and secondary traumatic stress in trauma nurses. J Trauma Nurs. 2014; 21: 160-169. Ref.: https://goo.gl/ozZk6R

50. Cieslak R, Shoji K, Douglas A, Meville E, Luszczynska A. A meta-analysis of the relationship between job burnout and secondary traumatic stress among workers with indirect exposure to trauma. Psychological Services. 2014; 11: 75-86. Ref.: https://goo.gl/8JY7C9

51. Schaufeli WB, Peeters MCW. Job stress and burnout among correctional officers: A literature review. International Journal of Stress Management. 2000; 7: 19-48. Ref.: https://goo.gl/qNH17p

52. Lambert E, Hogan N. The Importance of Job Satisfaction and Organizational Commitment in Shaping Turnover Intent: A Test of a Causal Model. Criminal Justice Review. 2009; 34: 96-118. Ref.: https://goo.gl/Valx2c

53. Bertee Jr. T. Predictors of Vicarious Trauma and Secondary Traumatic Stress Among Correctional Officers. PCOM Psychology Dissertations. 2012; 228. Ref.: https://goo.gl/v7SJQE

54. Brown KL, Benningfield M. Death row corrections officers: Experiences, perspectives and attitudes. Criminal Justice Review. 2008; 33: 524-540. Ref.: https://goo.gl/7CfM58

55. Crawley E. Bring it all back home? The impact of prison officers' work on their families. Probation Journal. 2002; 49: 277-292. Ref.: https://goo.gl//1Qimk

56. Norton L, Woods G, Brown L. Secondary Trauma in Forensic Settings: Effects on Court Personnel, Jurists, Jurors, and Correctional Officers. International Journal of Trauma Research and Practice. $2014 ; 1: 28-34$

57. Otero RF, McNally D, Powitzky R. Mental health services in adult correctional systems. Corrections Today. 1981; 43: 8-18. Ref.: https://goo.gl/YQ1in2

58. Senter A, Morgan Robert D, Serna-McDonald C, Marshall B. Correctional psychologist bumout, job satisfaction, and life satisfaction. Psychological Services. 2010; 7: 190-201. Ref.: https://goo.gl/LQbirF

59. Maslach C, Schaufeli WB, Leiter MP. Job burnout. Annu Rev Psychol. 2001; 52: 397-422. Ref.: https://goo.gl/kMYn37

60. Thomas WHNg, Sorensen KL, Eby LT. Locus of control at work: A meta-analysis. Journal of Organizational Behavior. 2006; 27: 1057-1087. Ref.: https://goo.gl/wDelba

61. Thoresen CJ, Kaplan SA, Barsky AP, Warren CR, deChermont $K$. The affective underpinnings of job perceptions and attitudes: A meta-analytic review and integration. Psychological Bulletin. 2003; 129: 914-945. Ref.: https://goo.gl/JNMVdd

62. Bateman TS, Crant JM. The proactive component of organizational behavior: A measure and correlates. Journal of Organizational Behavior. 1993; 14: 103-118. Ref.: https://goo.gl/Hx6Kf9

63. Alarcon G, Eschleman KJ, Bowling NA. Relationships between personality variables and burnout: A meta-analysis. Work \& Stress. 2009; 23: 244-263. Ref.: https://goo.gl/u28110

64. Celik GT, Oral EL. Burnout levels and personality traits-The case of turkish architectural students. Creative Education. 2013; 4: 124-131. Ref.: https://goo.gl/ZX8E98

65. Badger K. Catastrophe in the workplace: Impact of indirect trauma exposure on hospital social workers. University of Kentucky. 2005. Ref.: https://goo.gl/18n9o4 
66. Jiménez BM, Benadero MEM, Muñoz AR, Carvajal RR. The influence of personality variables on secondary traumatic stress. Behavioral Psychology. 2006; 14: 201-214. Ref.: https://goo.gl/UJ5fMF

67. Zerach G. Compassion fatigue and compassion satisfaction among residential child care workers: The role of personality resources. Residential Treatment For Children \& Youth. 2013; 30: 72-91. Ref.: https://goo.gl/BVw3nx

68. Eastwood CD, Ecklund K. Compassion fatigue risk and self-care practices among residential treatment center childcare workers. Residential Treatment for Children \& Youth. 2008; 25: 103-122. Ref.: https://goo.gl/gzX5KH

69. Gallavan DB, Newman JL. Predictors of burnout among correctional mental yealth professionals. Psychol Serv. 2013; 10: 115-122. Ref.: https://goo.gl/rgSLh1

70. Scheck CL, Kinicki AJ, Davy JA. A longitudinal study of a multivariate model of the stress process using structural equations modeling. Human Relations. 1995; 48; 1481-1511. Ref.: https://goo.gl/ziemV2

71. Janoff-Bulman R, Frieze IH. A theoretical perspective for understanding reactions to victimization. J. Soc. Is. 1983; 39: 1-17. Ref.: https://goo.gl/mI7LQ4

72. Janoff-Bulman R. Assumptive worlds and the stress of traumatic events: Applications of the schema construct. Social Cognition. 1989; 7: 113-139. Ref.: https://goo.gl/4xu6RK

73. Janoff-Bulman R. Shattered assumptions: towards a new psychology of trauma. New York: The Free Press. American J of Clinical Hypnosis. 1992; 36: 222-225. Ref.: https://goo.gl/kHla5W

74. Dekel S, Mandl C, Solomon Z. Shared and unique predictors of posttraumatic growth and distress. Journal of Clinical Psychology. 2011; 67: 241-252. Ref.: https://goo.gl/HMOGRF

75. Magwaza AS. Assumptive world of traumatized South African adults. J Soc Psychol. 1999; 139: 622-630. Ref.: https://goo.gl/bMhSkX

76. Bodvarsdottir I, Elklit A. Psychological reactions in Icelandic earthquake survivors. Scand J Psychol. 2004; 45: 3-13. Ref.: https://goo.gl/AIK3BG

77. Yuan C, Wang Z, Inslicht SS, McCaslin SE, Metzler TJ, et al. Protective factors for posttraumatic stress disorder symptoms in a prospective study of police officers. Psychiatry Research. 2011; 188: 45-50. Ref.: https://goo.gl/mRhD6f

78. Elklit A, Shevlin M, Solomon Z, Dekel R. Factor structure and concurrent validity of the world assumptions scale. J Trauma Stress. 2007; 20: 291-301. Ref.: https://goo.gl/R5Hkbv

79. Foa EB, Ehlers A, Clark DM, Tolin DF, Orsillo SM. The posttraumatic cognitions inventory (PTCl) Development and validation. Psychological Assessment. 1999; 11: 303-314. Ref.: https://goo.gl/7Wp8Ai

80. Jind L. Do traumatic events influence cognitive schemata? Scand J Psychol. 2001; 42: 113-120. Ref.: https://goo.gl/UPoqiR

81. Jeavons S, Godber T. World Assumptions as a measure of meaning in rural road crash victims. Aust J Rural Health. 2005; 13: 226-231. Ref.: https://goo.gl/RRcqj0

82. Solomon Z, lancu I, Tyano S. World assumptions following disaster. J Appl Soc Psychol. 1997; 27: 1785-1798. Ref.: https://goo.gl/ww8o9j

83. Ginzburg K. PTSD and world assumptions following myocardial infarction: A longitudinal study. Am J Orthopsychiatry. 2004; 74: 286-292. Ref.: https://goo.gl/P63C4R

84. Ullman SE. Attributions, world assumptions, and recovery from sexual assault. J Child Sex Abuse. 1997; 6: 1-19. Ref.: https://goo.gl/VkMWyN

85. Lee CS. Secondary traumatic stress in therapists who are exposed to client traumatic material Dissertation Abstracts International. 1996; 56: 4586

86. Rotter JB. Generalized expectancies for internal versus external control of reinforcement. Psychological Monographs: General \& Applied. 1966; 80: 1-28. Ref.: https://goo.gl/PVGoPf

87. Phillips WM. Purpose in life, depression and locus of control. J Clin Psychol. 1980; 36: 661-667. Ref.: https://goo.gl/7SnBB2

88. Reker GT. The purpose-in-life test in an inmate population: An empirical investigation. J Clin Psychol. 1977; 33: 688-693. Ref.: https://goo.gl/wxAl8Z

89. Sammon SD, Reznikoff M. Geisenger KF. Psychosocial development and stressful life events among religious professionals. Journal of Personality and Social Psychology. 1985; 48: 676-687. Ref.: https://goo.gl/cpX9y4 
90. Yarnell TD. Purpose-in-life test: Further correlates. J Individ Psychol. 1971; 27: 76-79. Ref.: https://goo.gl/Y7sV2N

91. Adams TB, Bezner JR, Drabbs ME, Zambarano RJ, Steinhardt MA. Conceptualisation and measurement of the spiritual and psychological dimensions of wellness in a college population. Journal of American College Health. 2000; 48: 165-173. Ref.: https://goo.gl/y4hxQc

92. Young MY. Moderators of stress in Salvadorian refugees: The role of social and personal resources. International Migration Review. 2001; 35: 840-869. Ref.: https://goo.gl/NamHkz

93. Maslach C, Jackson SE, Leiter M. Manual for the Maslach Burnout Inventory. CA: Consulting Psychologists Press. 1996; 191-218. Ref.: https://goo.gl/6Nk2Ss

94. Bride BE, Robinson MM, Yegidis B, Figley CR. Development and validation of the secondary traumatic stress scale. Res Soc Work Pract. 2003; 14: 1-16. Ref.: https://goo.gl/VblfbE

95. Rean AA. Handbook of personality assessment St Petersburg: St Petersburg University Press.

96. Jaracz K, Gorna K, Konieczna J. Burnout, stress and styles of coping among hospital nurses. Rocz Akad Med Bialymst. 2005; 50: 216-219. Ref.: https://goo.gl/LYhK6V

97. Storm K, Rothmann S. The validation of the Utrecht Work Engagement Scale in the South African Police Services. SA Journal of Industrial Psychology. 2003; 29: 62-70. Ref.: https://goo.gl/yqkSRc

98. American Psychiatric Association. Diagnostic and statistical manual of mental disorders Fourth edition text revision. https://goo.gl/dmqmyo

99. Malkina-Pykh IG. Association of job burnout and secondary traumatic stress among psychologists. Acmeology. 2010; 1: 79-89.

100. Bride BE. Prevalence of secondary traumatic stress among social workers. Soc Work. 2007; 52: 63-70. Ref.: https://goo.gl/s7I3K1

101. Schwartzberg SS, Janoff-Bulman R. Grief and the search for meaning: Exploring the assumptive worlds of bereaved college students. Journal of Social and Clinical Psychology. 1991; 10: 270-288. Ref.: https://goo.gl/Ot2zeC

102. Thurmer IS. An invitation to pay attention: A quantitative study of vicarious trauma and secondary traumatic stress in child advocacy employees, volunteers and interns. Dgree of Master of Social Work. Smith College School for Social Work, Northampton, Massachusetts, 2013.

103. Dekel R, Solomon Z, Elklit A, Ginzburg K. World assumptions and combat related posttraumatic stress disorder. The Journal of Social Psychology. 2004; 144: 407:420. Ref.: https://goo.gl/GLeYci

104. Foa EB, Zinbarg R, Rothbaum BO. Uncontrollability and unpredictability in post-traumatic stress disorder: an animal model. Psychol Bull. 1992; 112: 218-38. Ref.: https://goo.gl/9vDuPI

105.Foa E, Riggs D, Dancu C, Rothbaum B. Reliability and validity of a brief instrument for assessing post-traumatic stress disorder. Journal of Traumatic Stress. 1993; 6: 459-474. Ref.: https://goo.gl/OqefbO

106. Foa EB, Riggs DS. Post-traumatic stress disorder in rape victims. Annual review of psychiatry. 1993; 12: 273-303.

107. Hipps ES, Malpin G. The relationship of locus of control, stress related to performance- based accreditation, and job stress to burnout in public school teachers and principals. 1991; 46. Ref.: https://goo.gl/Gpaehj

108. Wong TP, Sproule CF. An attributional analysis of locus of control construct and the Trent Attribution Profile. Research with the locus of control construct. 1984; 3: 81-83. Ref.: https://goo.gl/16s3zG

109. Malkina-Pykh IG. An integrated model of psychological preparedness for threat and impacts of climate change disasters. 2013; 121-132. Ref.: https://goo.gl/6qmqal

110. Malkina-Pykh IG, Pykh YA. The Method of Response Function in Psychology and Sociology. Southampton Boston : WIT Press. 2012; 245. Ref.: https://goo.gl/XhHOo1 